\title{
Tecnologias da informação e comunicação nas políticas sociais: opacidade e ilusão democrata
}

\author{
Gabriele Faria ${ }^{1}$ \\ https://orcid.org/0000-0002-7435-9249 \\ ${ }^{1}$ Universidade Federal do Rio de Janeiro, Escola de Serviço Social, Programa de Pós-graduação em Serviço Social, Rio de \\ Janeiro, RJ, Brasil
}

Tecnologias da informação e comunicação nas políticas sociais: opacidade e ilusão democrata Resumo: Este artigo busca problematizar o uso das Tecnologias da Informação e Comunicação para acesso às políticas de seguridade social enquanto mecanismo que anuncia qualidade e celeridade, mas que encontra nos limites burgueses a chave de reforço das desigualdades, promovendo uma ilusão social-democrata, cujo compromisso é com a reprodução ampliada do capital. Para tanto, controle, violência e opacidade instauram-se em uma lógica empresarial, a qual coloca na ordem do dia uma engenharia que adensa sacrifícios, amoldamentos e apassivamento, inviabilizando uma perspectiva cidadã. Assim, buscamos mostrar que, por trás da modernização anunciada, se espraiam velhas práticas que indicam conspirar contra os direitos e avanços democráticos, reforçando a existência de uma democracia burguesa. A metodologia escolhida consiste na análise bibliográfica e documental como forma de mediatizar nossa reflexão acerca do tempo presente, cujo movimento é desalentador. Para isso, tomaremos o método dialético para dar curso a uma análise racional de uma era barbarizante.

Palavras-chave: Tecnologias; Políticas sociais; Democracia; Opacidade.

\section{Information and communication technologies in social policies: lack of transparency and democratic illusion}

Abstract: This article discusses the use of Information and Communication Technologies to access social security policies as a mechanism of quality and speed but finds in the bourgeois limits the reinforcement of inequalities, fostering a socialdemocratic illusion, committed to the expanded reproduction of capital. To this end, control, violence, and lack of transparency e established in a business logic that puts on the agenda a kind of engineering that intensifies sacrifices, shaping, and passiveness, making a citizen perspective unfeasible. Thus, we seek to show that, behind the modernization announced, old practices are spread, conspiring against democratic rights and advances, reinforcing the bourgeois democracy. The methodology adopted consists of bibliographic and documental analysis to mediate our reflection regarding the present time, which is in a movement discouraging. To do so, we follow the dialectical method to give course to a rational analysis of a barbaric era.

Keywords: Technologies; Social policies; Democracy; Lack of transparency.

Recebido em: 21.06.2021. Aprovado em: 31.08.2021. Revisado em: 14.09.2021.

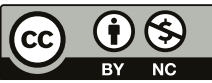

Este é um artigo publicado em acesso aberto (Open Access) sob a licença Creative Commons Attribution NonCommercial, que permite uso, distribuição e reprodução em qualquer meio, sem restrições desde que sem fins comerciais e que o trabalho original seja corretamente citado. 


\section{Introdução}

O presente trabalho é um fragmento de algumas aproximações iniciais do cenário contemporâneo atravessado pelas tecnologias da informação e comunicação (TICs). A partir desta ideia, conjecturaremos a análise do direito como outorga, legitimando o controle de comportamentos, muitas vezes moldados em equipamentos estatais, que reiteram práticas ultraconservadoras e ratificam o aparato estatal como necessário à reprodução capitalista, donde a cidadania se põe como um recurso ideológico fundamental via sua função precípua de criação de formas jurídicas, organizacionais e instrumentais. Tais formas, assim, funcionam como resposta a poderes específicos, por vezes divergentes, consentindo regular a dominação de classes e administrar a barbárie.

Neste contexto, de acordo com Antunes (2020), no avolumar da indústria 4.0 — que compõe o universo maquínico-informacional-digital - a partir de 2011 processos produtivos se espraiam ainda mais automatizados e robotizados com consequências jamais vistas na vida da classe trabalhadora e no mundo do trabalho. Tal fato leva ao aprofundando a vigia, a precarização e da a intensificação, sobretudo no setor de serviços, ramo de maior interesse do mercado, em que políticas de assistência social, saúde e previdência social se inscrevem, garantindo reprodução ideológica e material de classe.

Enquanto objetos de intervenção do Estado, tais políticas públicas são atravessadas por interesses antagônicos, cujas regulações no contexto neoliberal dinamizam soluções rápidas e menos onerosas cravejadas de anti-humanismo - via instrumentos modernos de controle dos expropriados e afrouxamento da democracia. Essa engenharia do Estado moderno põe em xeque a democracia, diante de um modelo que pressupõe melhoria na gestão e acesso aos serviços públicos. Essa ação converge com o conteúdo político presente no caldo de cultura brasileiro, reafirmando a manutenção da natureza capitalista, agudizando inúmeras desigualdades e opressões, sobretudo quando, ao tornar processos mais controlados para formatar decisões, incide sobre condições de liberdade, equidade e privacidade, sobrevindo, assim, sobre a democracia.

Dividido em três momento, o artigo inicia uma reflexão acerca da função do Estado no capitalismo maduro. Na segunda parte, apresentaremos a incompatibilidade entre igualdade de direitos no capitalismo, apesar do reconhecimento do status de cidadão. Por último, elucubraremos as TICs tomando como exemplo seu uso na seguridade social enquanto potencializadora de uma ilusão democrata que, diante dos limites burgueses, reforça desigualdades e restringe a cidadania.

\section{Um estado árbitro de uma estrutura desigual}

Pensando o Estado enquanto um fenômeno essencialmente capitalista, Mascaro (2013) o aponta como necessário à reprodução do capital, afiançando a troca de mercadorias e a exploração da força de trabalho. O mesmo autor configura o Estado como um terceiro elemento na relação dinâmica entre capital e trabalho, fundamental na formação social, quer seja da burguesia, quer seja dos trabalhadores. Dessa forma, apresentase como necessário às relações sociais, permitindo ao explorador e ao explorado qualificarem-se enquanto sujeitos de direitos.

O que fica evidente, portanto, é que o Estado, enquanto aparato indispensável à reprodução das relações sociais cria o cenário para condições de reprodução do capital. Nesta estrutura, identifica-se o qualificativo de democrático ao campo político ${ }^{1}$ (MASCARO, 2013), propiciado pelas hastes jurídicas uma igualdade formal, impensável sem a categoria valor das mercadorias, na qual os indivíduos se lançam juridicamente livres e iguais.

Assim, da forma-mercadoria deriva a forma democrática, em que o Estado apresentará desenhos variados para dar conta das demandas colocadas pelas classes antagônicas, donde a cidadania — enquanto conjunto de direitos determinados por um Estado, que é expressão da sociedade civil burguesa - não pretende universalizarse, mas tencionar a ordem capitalista no tempo e no espaço via conceitos formais de igualdade e liberdade, os quais indicam que, dentro de uma filosofia adaptadora da sociedade, tangenciam apenas interesses individuais. Então, se trocas mercantis assumem equivalência por meio do intercâmbio de dois proprietários de diferentes produtos, cabe ao Estado ser o árbitro imparcial que nega a estrutura desigual entre capitalista e trabalhador, bloqueando desigualdades - elemento necessário para a alienação do homem enquanto proprietário de si. 
Sem dúvida, este padrão é atravessado por uma base econômica na qual se apresentam concessões necessárias em termos de legislações, normas, políticas, que são fundamentais nos marcos de uma democracia, mas insuficientes, tendo em vista não ser o horizonte a real participação dos cidadãos nas decisões que os afetam. Tal situação reitera o caráter puramente formal desta suposta igualdade universalizante e negocial da liberdade, encerrando, deste modo, aspectos fetichizantes, os quais demarcam violências, que naturalizam e reforçam a identidade do capitalismo e, por assim dizer, coloca em crise o conceito de cidadania.

Nessa dinâmica, a burguesia trata de utilizar o espaço Estatal para interesse próprio por meio de formas sutis apresentadas como novidades importantes para todos, tratadas com neutralidade, logo, produzindo convencimentos mistificados garantidores do apassivamento, o que revela a particularidade do processo ideológico (IASI, 2017).

Com a proeminência da indústria 4.0, ou Quarta Revolução Industrial, em 2011 (ANTUNES, 2020), o incremento de softwares, máquinas, inteligência artificial — estruturados por meio das TICs — revela um avanço da ciência e da técnica, cujas implicações forjam uma dinâmica para explorar novos nichos de valorização do capital superacumulado, intensificar a exploração e a expropriação do trabalhador a partir de novos mecanismos robotizados, com fluxo de dados tecidos em dispositivos criados pela mão humana - portadora de certa intencionalidade - com maior poder para gerir condutas, prever e moldar comportamentos de forma oculta.

Falamos de um movimento moderno indispensável à reprodução capitalista, que pretende se apoderar tanto do trabalho como da imaginação e dos modos de vida coletivos por meio de dados pessoais coletados e armazenados em bases governamentais, rodando em plataformas digitais diversas, inclusive na infraestrutura de funcionamento das políticas sociais ${ }^{2}$, necessárias ao acesso via protocolos codificados, gerenciados por algoritmos de performativa matemática, que compelem governos e Estados a ajustar estruturas legais e democráticas (JURNO, 2021).

Nessa lógica, contrariando o prenuncio de que o mundo maquínico traria tão somente benefícios à classe trabalhadora, a tendência que se ativa - sobretudo com a abertura da crise de 2008 - é a de um capitalismo de plataforma ${ }^{3}$, cada vez mais disposto e planejado globalmente para a exploração, que se dará de modo naturalizado e conveniente ao exercício do poder. É um perfil de capitalismo projetado a partir de novas bases e novos métodos, apresentados por Dardot e Laval (2016) como Uma nova razão de mundo, cuja direção se inscreve sob a lógica empresarial que persegue eficiência e eficácia e almeja conformar o ideal de trabalho e trabalhador livre à competição, sem que o Estado seja responsabilizado. Uma norma, portanto, funcional ao nexo privado ao camuflar o caráter fictício de soluções contraditórias, que dão vivacidade ao movimento contrarreformista ${ }^{4}$ em escalada desde 1990, o qual culpabiliza os direitos pela crise econômica e orienta a forma estatal.

Para além de intensificar o domínio e a fiscalização dos trabalhadores a partir de novos modos de gerenciamento da força de trabalho e organização do processo produtivo, essas novas estratégias de gestão dinamizadas pelas TICs podem potencializar um melhor planejamento dos serviços públicos com soluções mais inteligentes. Contudo, diante de uma orientação hegemônica do capital, se expressam estruturando, segundo Antunes (2020), novos mecanismos de extração do sobretrabalho, bem como novos mercados, modelos de negócios e formas de pensar os indivíduos (SILVEIRA, 2021). Isso em um mundo conectado, imbuído de sistemas sob composições algorítmicas, processadas para organizar a fila, traduzir, modificar, desvendar e até distorcer de acordo com aquilo que foi programado. Em geral, realizado de modo opaco por engenheiros de empresas privadas, que proclamam modernidade e neutralidade para monitorar, acompanhar condicionalidades, produtividade dos profissionais, cruzamento de dados com outras bases, deferimentos e indeferimentos.

O que importa destacar é que o contexto desse incremento tecnológico é o mesmo do neoliberalismo de dominância empresarial, cujos dados, segundo estudos de Silveira (2021, p. 34) aparecem junto às ideias deste ideário como o novo petróleo da internet e a nova moeda do mundo digital. Logo, para além de reconfigurar a sociedade a partir de novas posturas e sujeições, os dados reconfiguram a economia e o capital a partir de relações comerciais, cujos dados despontam, segundo o mesmo autor, como modelo de negócio capaz de capturar informações pessoais, conhecimentos, bem como desvendar presente e futuro.

Assim, prenunciando uma administração pública mais eficiente, convocam-se usuários dos serviços a uma adaptabilidade em rede, em que ferramentas tecnológicas são utilizadas hoje nas políticas sociais importantes para garantir um mínimo necessário para a reprodução da classe trabalhadora - em diversos momentos do processo de gestão, organizando a relação entre Estado e sociedade. Estabelece-se assim, uma 
nova norma de conduta exacerbadora da individualização, recodificadora de modos de vida, que culpabilizam os sujeitos por seu fracasso, retirando do Estado a tarefa de representante coletivo, mas reiterando a perspectiva de organizador de uma lógica despolitizadora de conflitos e dinamizadora de um alvará moral em que vidas são apreendidas, dirigidas e avaliadas como em uma empresa, em que questionamentos colocam-se fora da possibilidade de reconhecimento do sujeito moral autônomo e responsável, ou seja, o desejado nesta engenharia social silenciadora (SAFATLE, 2020).

Outrossim, institui-se o discurso da democratização do acesso e da maior celeridade nos serviços capitaneados pelo Estado, cuja burla de garantias democráticas em face do comando e gerenciamento das contratendências ${ }^{5}$ demarca o antagonismo estrutural entre a universalização da cidadania e a lógica que impera no modo de produção capitalista, donde o Estado vem assumindo o lugar de legitimador dos interesses do capital e burlando interesses democráticos a partir de um contexto com características autoritárias, demarcador da incompatibilidade entre democracia e capitalismo, ao passo que respeito, proteção e direitos são usurpados convocando-nos a refletir quanto aos significados desse movimento e para qual cidadania está dirigido.

\section{Ser cidadão no capitalismo: do que se trata?}

A partir da necessidade de regular a convivência humana a cidadania, vinculada à democracia, cria condições para a racionalização do pensamento. É experimentada inicialmente pelos gregos por meio dos direitos políticos, em que homens ficavam entregues à sua capacidade de decisão, porém, ainda longe de uma dimensão universal, já que, segundo Coutinho (2018), grande parte da população ateniense estava excluída dos direitos da cidadania naquela época - entre eles, escravos, mulheres e estrangeiros - , sendo a democracia exclusividade dos proprietários de terras. Assim, o ser cidadão definia-se pela liberdade e igualdade entre os pares, ou seja, homens livres, proprietários de terras e de conhecimento. Não havia um status único e uniforme.

Ainda na tentativa de demarcar o caráter histórico da cidadania, na contribuição processual de Marshall ${ }^{6}$ na Inglaterra do séc. XVIII, instituem-se três níveis de direitos determinantes para o autor no estabelecimento de políticas igualitárias e fundantes no debate do reconhecimento dos direitos sociais como subsídios de cidadania. A partir de uma ordem cronológica, direitos civis, políticos e sociais se fariam presentes no mundo moderno na concepção do pensador. Contudo, tal ordem de ocorrência ao longo da história não apresenta a mesma aparência nos diversos continentes, a exemplo do Brasil, que inicia sua experiência enquanto afiançador de direitos sociais, com coexistência de aspectos coercitivos e estabelecimento de consensos concebidos de forma corporativa, o que reforça os traços perversos da nossa formação estatal (COUTINHO, 2018, p. 238).

Entre os níveis de direitos estão os direitos civis, que preconizam a liberdade de ir e vir, funcionais à época, ou seja, direitos que os homens têm sob sua vida privada e de proteção contra abusos do governo. Nesta ordem, traz a exigência de uma institucionalidade mediada por profissionais que façam valer seu cumprimento (juízes, tribunais). Deste modo, estão postos na essência desses direitos os interesses particularistas e excludentes ao garantir liberdade para a venda de mão de obra sem, no entanto, garantir que os trabalhadores tenham a propriedade do fruto do trabalho. Logo, é o direito civil que permitirá a igualdade para a busca individual via liberdade formal, o que não significa a redução das necessidades, demarcando a violência, uma vez que não há nem igualdade, nem liberdade efetiva, o que vem demonstrar a insuficiência na cidadania moderna.

Os direitos políticos retomam a cidadania própria dos gregos, em que um número significativo de pessoas participava da esfera pública. Eles vão garantir o direito de votar e de ser votado, condição à participação que se concretizará ao passo que justiça e polícia o viabilizem institucionalmente. Tais direitos são concedidos em decorrência dos direitos civis, na medida em que os trabalhadores são livres para manifestar-se, ou seja, ao participar da vida pública, estes podem impor limites aos capitalistas. Assim, com esse direito moderno, acreditava-se na possibilidade de cada grupo ter a mesma oportunidade de igualdade, mas, dadas as características coercitivas dos aparelhos do Estado, transmuta-se em criminalização das organizações e coletivos populares, demarcando nova forma de violência Estatal.

Já os direitos sociais — que por anos foram negados, acusados de estimular a preguiça - se ampliam na cidadania moderna enquanto possibilidade de acesso a bens e serviços, redução da estratificação social, porém sempre pautando-se no mínimo, sem a perspectiva de integração de cidadãos à participação na riqueza 
produzida, dando, por conseguinte, sustentabilidade aos ideais capitalistas, orientando-se, assim, por uma pífia moeda de troca para conter o agravamento da questão social.

Nas análises de Marshall, é possível observar a necessidade de um aparato institucional forte e capaz de propiciar um mínimo de bem-estar. Por outro lado, há o reconhecimento da funcionalidade desses direitos à manutenção de um sistema adequado às necessidades capitalistas, no qual a igualdade formal enquanto propulsora da cidadania nos termos marshallianos, segundo Boschetti (2018, p. 83), negligencia o acesso de todos a melhores condições, mas legitima a igualdade de status. Nele, os sujeitos buscam suas satisfações individualmente, o que implica não considerar uma sociedade dividida em classes e, por consequência, na instituição de direitos burgueses, corroborando as análises de Marx (2012) na obra Crítica do Programa de Gotha. O autor trata da incompatibilidade entre igualdade e direitos no capitalismo, sobretudo a partir do ocultamento da distinção de classes.

Desse modo, é possível inferir que tal cidadania proposta nada mais é do que a cidadania burguesa, a qual fetichiza liberdades funcionais ao mercado, que tem no trabalhador um pássaro livre para ser explorado, sem, contudo, libertar-se da opressão presente nas relações capitalistas. Por outro lado, há no status de cidadão o reconhecimento formal dele pelo Estado, assegurando não só sua emancipação humana, mas também acesso ao mínimo de bens e serviços. Assim, no que tange à cidadania, parece haver um consenso de que tal conquista implica direitos e deveres, bem como de que estes precisam prosseguir no âmbito da universalização. Isso abre a possibilidade concreta da instituição democrática via Estado, o que não significa que uma ordem democrática anule a efetividade da dominação, já que a legalidade não é necessariamente a defesa das minorias, impondo questionamentos ao valor universal da democracia. Isso especialmente quando se pretende conservar formas sociais postas historicamente e que se refratam a cada quadra histórica, reiterando que o capitalismo plenamente maduro não é o capitalismo com direitos, ou seja, os direitos não estão em seu horizonte. Nessa dinâmica, caberá ao Estado o papel fundamental na construção da norma que rotineiramente vai contemplar uma classe em detrimento da outra.

Longe de nós tirarmos a importância que têm os direitos enquanto conquista dos trabalhadores. Cabenos ponderar as características essências presentes neles e em sua forma de acesso, sobretudo, a partir dos interesses em cena, que controlam e ditam as regras no interior do Estado e promovem, nos termos de Demier (2017), uma blindagem dos aparatos institucionais a qualquer perspectiva progressista que questione ou tencione os interesses das elites.

De acordo com Coutinho (2018), apesar de a democracia ser um espaço de disputas posto em terreno desigual, há nela potencial para pensarmos em que medida a classe trabalhadora tem, pela via do Estado, possibilidades de ter assegurados seus direitos. Entretanto, a máquina estatal não mostra tamanha autonomia em relação à burguesia e, por isso, ordena suas funções políticas, econômicas e ações coercitivas em prol desta, oferecendo, assim, uma democracia restrita.

Dessa forma, sistemas protetivos estruturados democraticamente na Constituição Federal de 1988 são alvo de recorrentes desmontes dinamizados por uma ordem que tratou de solapar a seguridade social com ideologias antiestado e de retomada do crescimento à custa da expropriação dos trabalhadores. Assim, Assistência Social, Saúde e Previdência Social engendram uma proteção inconclusa, tencionada por um Estado que radicaliza reformas concretas, com vistas a desarticular o sistema para submetê-lo ao mercado como estratégia prioritária em resposta à crise.

Nessa esteira, a forma política estatal adota um design inovador nas políticas sociais de seguridade social a partir de novas tecnologias direcionadas não à ampliação dos serviços, mas ao controle, à predição, à redução dos gastos e à expropriação dos direitos, em que liberdade e igualdade são negligenciadas demarcando limites à cidadania.

\section{Qual cidadania se coloca junto às TICs?}

A importância do uso de tecnologias enquanto instrumento de gestão pública no Brasil aparece em documentos oficiais (IBGE, 2009) com destacada prioridade segundo orientações de organismos internacionais. Estas tecnologias ingressam e se expandem no contexto de contrarreformas do Estado com impacto direto nas políticas sociais, sobretudo, naquelas que congregam o público mais empobrecido. Desde 1990, a política de 
saúde já contava com sistemas de informação atualizados ao longo dos anos; a Assistência Social os adota a partir de 2008; a Previdência Social, apesar de possuir base de dados anterior, promove incremento tecnológico importante a partir de 2016.

O que se observa é que a noção de governo eletrônico posta nos estudos de Chahin (2004) — proclamadora da prestação de serviços públicos disponíveis vinte e quatro horas por dia, sete dias por semana de modo mais eficiente, barato e sem tencionar a cidadania - encontra desafios para se espraiar como prometido, já que, desde seu nascedouro, está intimamente vinculada à redução nos gastos, sobretudo, na esfera da reprodução social, em face dos interesses do capital direcionados de maneira resoluta pelo Estado.

Longe de nós desqualificar a importância desses sistemas informacionais para gestão e administração dos serviços, afinal há neles grande potencial para um melhor planejamento das ações. Entretanto, apesar de anunciar transparência, celeridade e otimização, o cenário que os conforma de reorientação organizacional na lógica do desfinanciamento demarca o imbróglio, já que, muitas vezes, estes aspectos positivos não predominam em relação a outros interesses ocultados e que apontam a contradição presente nessas novas tecnologias. Tal fato se observa na Assistência Social por meio do Cadastro Único ${ }^{7}$, que vem produzindo coleta de dados de seus usuários com vistas à vigilância e ao monitoramento dos mais pobres; na saúde, pelo sistema e-SUS, que realiza a coleta de dados, armazena atividades realizadas preconizando produtivismo que impactará o financiamento do sistema de saúde; na Previdência Social, com o aplicativo Meu INSS ou por atendimento telefônico 135, em que se incute uma tendência de acesso exclusivamente digital dos usuários, pontuações biomédicas pouco explicáveis, resultando em restrição do direito, alta produtividade, controle de metas que impactam salários, redução da autonomia e até da figura do servidor.

Assim, importa analisarmos uma dinâmica que nos parece alterar liberdades de escolha, autonomia decisória, incorporando uma universalidade sem totalidade de modo naturalizado em uma estrutura desigual — anunciada com supostos benefícios de mapeamento rápido, tráfego de enorme volume de dados, impondo produtivíssimo aos trabalhadores, além de não considerar o acesso à internet ${ }^{8}$, cujas dificuldades de manuseio limitam o direito que, apesar de formal, não está para todos.

Diferentemente da análise de Pierre Levy (1999), não naturalizamos a ideia de que cada novo sistema produz seus excluídos como algo inevitável. Nossa defesa é a de que a dimensão da desigualdade não está posta por opção individual, mas construída em estruturas desiguais. Nesta mesma direção, Silveira (2008, p. 54) ressalta que um uso de fato democrático deve considerar não só a dificuldade de acessar por razões sociais, econômicas, geográficas, mas também a partir das habilidades de manuseio que implicaria maiores níveis educacionais, fomentaria um uso mais autônomo e não subordinado, tal qual estamos a observar e que deixa muita gente de fora, seja pela falta do smartphone e de computadores, pela pouca habilidade ou restrito acesso à internet.

Com a emergência sanitária imposta pela pandemia do novo coronavírus - Covid-19, sentida no Brasil a partir de março de 2020, o resguardo à vida invocou como principal medida de mitigação do contágio a necessidade de isolamento, impondo aos pobres a difícil escolha entre morrer pelo vírus ou de fome. Assim, além da alta contaminação entre os mais vulneráveis, o cenário denuncia a informalidade e um abissal desemprego de 12,4\% (PNAD Covid-19, 2020). Isso fez com que o Estado deliberasse auxílios necessários à estratégia de segurança nacional, bem como a coesão e reprodução material de parcela da população, que experimenta como maior radicalidade as desigualdades.

O que nos chama a atenção é que, diante desse panorama, as bases de dados do Cadastro Único foram silenciadas para o planejamento em detrimento da criação de aplicativos de autocadastramento ${ }^{9}$, a exemplo do Auxílio Carioca; do SuperaRJ; e do Auxílio Emergencial ${ }^{10}$. Segundo pesquisa da Fundação Getúlio Vargas (2021), tal fato deixou um quantitativo importante das classes D e E sem o benefício, colocando a proteção social na contramão do seu acesso, reafirmando o caráter autoritário das decisões, além de demostrar estímulo à bancarização dos pobres, já que junto destes benefícios está a necessidade da abertura de contas em bancos digitais como condição necessária ao crédito e à possibilidade de empréstimos. Esse é um elemento importante na dinâmica do capital financeiro, em que todas as relações são atravessadas pela intermediação bancária, rendendo juros a banqueiros pela cooptação daqueles mais pobres atendidos pelas políticas sociais, ora rastreados e inseridos nas carteiras do sistema financeiro, cuja faceta do capital a juros é endossada pela fala do presidente Jair Bolsonaro àqueles que pedem prorrogação do auxilio emergencial: "devem ir no banco $e$ fazer empréstimo" (COLETTA, 2021, p. 1). 
Com o uso das TICs para acessar direitos por aqueles cujo perfil majoritário é de escolaridade não reportada e acesso limitado, observa-se uma mercadorização e desuniversalização dos direitos e serviços públicos, subordinados ao pensamento neoliberal, que institui uma lógica do campo de dominação mantenedora das desigualdades. Isso demarca um caráter de cidadania que negligencia o acesso por todos aos seus direitos, sem abandono da igualdade de status, ora fetichizada, como a liberdade, já que esse acesso é condicionado ao uso de dados privados confiados ao Estado - sem opção de escolha - ainda com leis de proteção de dados incipientes e autoridade nacional de proteção não definida, o que pode facilitar o acesso desses dados por terceiros.

Em face de ações hipoteticamente democráticas, coloca-se o apassivamento de seguimentos vulneráveis frente a um regime de fluxo de informações necessárias ao controle das atividades de dispositivos digitais conectados em tempo real para extrair modelagens operadas por algoritmos que rodam em sistemas computacionais matematizadores das relações sociais. Isso tudo nos remete a um revigorar do positivismo para interpretação do movimento social, funcional às exigências conservadoras, das quais submergem expressões reacionárias de interesse dominante, articulando-se, segundo Escorsim (2011), ao ideário neoliberal, nada comprometido com aspectos democráticos.

Nesse sentido, atividades antes feitas por servidores públicos são substituídas por artefatos técnicos que engendram a inteligência artificial para que as máquinas imitem, sintam, compreendam e aprendam como os humanos. Segundo Silveira (2021), a partir desse aprendizado de máquina possibilitado pela captura de dados, as informações vão se alterando, com vistas a melhorar a experiência, contudo, aumentando a opacidade.

Em geral, para o acesso a serviços, disponibiliza-se mais informações do que as efetivamente necessárias, a fim de gerar probabilidades. Elas funcionam como receitas de bolo, em que, a partir de uma entrada, gera-se uma saída que não considerou uma série de fatores. Em entrevista ao canal Tecnopolítica em 2018, a matemática Amanda Yumi destaca que, à medida que esse banco de dados aumenta, seus códigos se alteram em tempo real, assim, nem quem programou pode explicá-los, e impor limites a essas máquinas aumentaria a propensão ao "erro" ou prejuízo, ora impensáveis.

Tais aspectos denotam ampliar o desequilíbrio das condições de igualdade, quer seja pela invasão de privacidade que produz, já que, para o acesso, não resta outra alternativa senão a entrega de dados privados; pela possibilidade real de esses aplicativos instalados em celulares estarem rastreando pessoas, fazendo, com isso, predições, reforçando um histórico de desigualdades funcional a uma classificação do que representa perigo ou é aceitável moralmente; pela probabilidade de estarem usando aplicações de neurociência em teleconsultas na saúde ou nos teleatendimentos da Previdência Social, cujas expressões faciais podem possibilitar apreensão de comportamentos sem que os sujeitos tenham ciência dessa captura - que, segundo estudos ${ }^{11}$, podem apresentar uma vigilância discriminatória de raça, gênero e cultural, colocando os usuários numa posição de extrema vulnerabilidade e reforçando desigualdades (CODED... 2020); pela possibilidade de maior controle e monitoramento de supostos fraudulentos; e pela perda de autonomia via resultados performados sem que os profissionais ou usuários conheçam os critérios.

Essa dinâmica, pouco discutida com os mais afetados, é conduzida por engenheiros de setores corporativos numa clara transferência tanto do poder de coleta quanto da interpretação desses processos automatizados para decidir critérios de acesso, organizar filas, formatar opiniões e decisões. Essa dinâmica age sob condições mínimas de igualdade, exterminando espaços de debates, fortalecendo o senso punitivo ou a organização de atuações autoritárias e menos as ações que desafiam o cotidiano dos usuários das políticas sociais, os quais subordinam-se com pouco espaço de manobra, via uma liberdade limitada de forma intencional.

Os dados são treinados por impressões pessoais que rastreiam e decidem o que merecemos, logo, podem estar refinando a focalização e engendrando a financeirização, tomadas a partir de uma fé na modernidade, a qual reascende o passado, negligencia desumanidades produzidas por ferramentas invasivas, controladoras e punitivas que, segundo Virginia Eubanks (2019 apud FAST, 2019) ${ }^{12}$, são experimentadas com os maiores requerentes: os pobres. Então, como garantir justiça social e cidadania num sistema cujos algoritmos desconhecemos? Como pressupor igualdade quando, sob a hegemonia neoliberal, a invasão de privacidade, a perseguição e a indiferença são naturalizadas desqualificando valores democráticos?

Destarte, nos parece que o tempo presente conspira contra os direitos e os avanços democráticos gravitando nos problemas sociais uma solução instrumental tecida em uma racionalidade ideológica funcional à conservação de formas sociais pouco orientadas às escolhas democráticas e à garantia dos direitos. 


\section{Considerações finais}

O que se revela é que, nos marcos da democracia burguesa que se conformam, a expansão que se delineia é apenas a do capital, ou seja, todas as pretensões de valores humanos se subordinarão à sua expansão. Nesta lógica, modernos instrumentos se lançam à meta determinada, de forma fetichizada, operada em uma estrutura compatível, ora verticalizada, autoritária, e que se reverte em grande armazenador de dados privados para acesso a direitos. Para tanto, algumas questões se colocam: que informações estão sendo usadas e para quais objetivos? Que variáveis são definidas para determinar a decisão? Cabe em uma democracia a perseguição e/ ou a interdição?

Quem sofre os efeitos destes instrumentos apologéticos da democracia precisa compreender suas regras, cuja explicabilidade depende dos interesses em jogo, subversivos de conteúdos familiares, mas fora do alcance dos indivíduos capturados. Diante disso, nega-se toda forma jurídica para viabilizar a direção desejada nos marcos do capital (LUKÁCS, 2007, p. 57-58), prevalecendo, então, disposições antidemocráticas das classes dominantes, cujos limites estão definidos pelo capital, ora interessado em interditar, vigiar, produzir subjetividades de forma opaca e voltadas para o consumo.

\section{Referências}

ANTUNES, R. Uberização, trabalho digital e Indústria 4.0. São Paulo: Boitempo, 2020.

BEHRING, E, BOSCHETTI, I. Política Social: Fundamentos e história. São Paulo: Cortez, 2011.

BOSCHETTI, I. Expropriação e Direitos no Capitalismo. São Paulo, Cortez, 2018.

BRASIL. Lei $\mathrm{n}^{\circ}$ 13.982, de 2 de abril de 2020. Altera a Lei $\mathrm{n}^{\circ}$ 8.742, de 7 de dezembro de 1993, para dispor sobre parâmetros adicionais de caracterização da situação de vulnerabilidade social para fins de elegibilidade ao benefício de prestação continuada (BPC), e estabelece medidas excepcionais de proteção social a serem adotadas durante o período de enfrentamento da emergência de saúde pública de importância internacional decorrente do coronavírus (Covid-19) responsável pelo surto de 2019, a que se refere a Lei n ${ }^{\circ}$ 13.979, de 6 de fevereiro de 2020. Brasília DF: Presidência da República, [2021]. Disponível em: http://www.planalto.gov.br/ ccivil_03/_ato2019-2022/2020/lei/113982.htm. Acesso em: 5 set. 2021.

BRASIL. Instituto Brasileiro de Geografia e Estatística (IBGE). Pesquisa Nacional por Amostra de Domicílios Contínua (PNAD) COVID-19. Microdados [Internet]. Rio de Janeiro: IBGE; 2020 [acessado 2021 Jun 24]. Disponível em: https://covid19.ibge.gov.br/ pnad-covid/trabalho.php

CHAHIN, A. et al. E-gov. Br: a próxima revolução brasileira. São Paulo: Prentice Hall, 2004.

CODED BIAS. Direção de Shalini Kantayya. Utah US: Shalini Kantayya, 2020. DVD (90 min.)

COLETTA. R. D. É só ir no banco e fazer empréstimo, diz Bolsonaro sobre auxílio emergencial. Folha de S. Paulo, São Paulo, 1 jun. 2021. Disponível em: https://www1.folha.uol.com.br/mercado/2021/06/e-so-ir-no-banco-e-fazer-emprestimo-diz-bolsonaro-sobreampliacao-do-auxilio-emergencial.shtml. Acesso em: 5 set. 2021.

COUTINHO, C. N. A Democracia como Valor Universal. In: TEIXEIRA A. M P.; ALVES G. L. (org.). Ensaios de Crítica Literária, Filosofia e Política. Rio de Janeiro: PPGSS/UFRJ, 2018.

DARDOT, P.; LAVAL, C. A nova Razão do Mundo: Ensaio sobre a sociedade neoliberal. São Paulo: Boitempo, 2016.

DEMIER, F. Depois do Golpe. A Dialética da Democracia Blindada no Brasil. Rio de Janeiro: Mauad Editora, 2017.

ESCORSIM NETTO, L. O conservadorismo clássico. Elementos de caracterização e crítica. São Paulo: Cortez, 2011.

FAST, K. Automatizando as Desigualdades: entrevista com Virginia Eubanks. Digilabour, São Leopoldo, 1 set. 2019. Disponível em: https://digilabour.com.br/2019/09/01/eubanks-automatizando-as-desigualdades. Acesso em: 5 set. 2021.

FUNDAÇÃO GETÚLIO VARGAS. Impactos do Covid. Centro de Políticas Sociais, 2021. Disponível em: https://cps.fgv.br/impactosdo-covid. Acesso em: 5 de set. 2021.

GROHMANN, R. Trabalho plataformizado e lutas de classes. Revista Margem Esquerda São Paulo, n. 36, 2021.

IASI, M. Política, Estado e Ideologia na trama conjuntural. São Paulo, ECP, 2017.

IBGE. O setor da tecnologia da informação e comunicação no Brasil 2003-2006. In: Estudos e Pesquisas de Informação Econômica, Ministério do Planejamento, Rio de Janeiro, n. 11, 2009. Disponível em: https://biblioteca.ibge.gov.br/visualizacao/livros/liv41716. pdf $>7 / 9 / 2020$. Acesso em: 5 set. 202.

JURNO, A. Plataformas, algoritmos e moldagem de interesses. Revista Margem Esquerda, São Paulo, n. 36, 2021.

LEVY, P. Cibercultura. São Paulo: Editora 34, 1999. 
LUKÁCS, G. O Jovem Marx e outros Escritos de Filosofia. Rio de Janeiro, Editora UFRJ, 2007.

MARSHALL, T. H. Cidadania e Classe Social. In: MARSHALL, T. H. Cidadania, Classe Social e Status. Rio de Janeiro: Zahar, 1967. MARX, K. Crítica do Programa de Gotha. São Paulo: Boitempo, 2012.

MASCARO, A. L. Estado e forma política. São Paulo, Boitempo, 2013

SAFATLE, V.; JUNIOR, N. Neoliberalismo como gestão do sofrimento psíquico. São Paulo, Autentica, 2020.

SILVEIRA, S. A. A noção de exclusão digital diante das exigências de uma cibercidadania In: HETKOWSKI, T. M. (org.). Políticas públicas \& inclusão digital. Salvador: EDUFBA, 2008. p. 43-65.

SILVEIRA, S. A. O mercado de dados e o intelecto geral. Revista Margem Esquerda, São Paulo, n. 36, 2021.

YUMI, A. As implicações políticas dos algoritmos. [Internet] Youtube (2018, dezembro, 18) Podcast Tecnopolítica. [acessado 2021 Jun 24] Disponível: https://www.youtube.com/watch?v=aRkqfx_XTVY\&t=2199s

\section{Gabriele Gomes Faria}

fwgf20@gmail.com

Mestre em Política Social pela Universidade Federal Fluminense (UFF)

Doutoranda pelo Programa de Pós-Graduação em Serviço Social da Universidade Federal do Rio de Janeiro (UFRJ)

\section{UFRJ}

Avenida Pasteur, 250, Urca, Rio de Janeiro

RJ, Brasil

CEP: 22290-240

\section{Agradecimentos}

À minha orientadora, Alejandra Pastorini.

Agência financiadora

Não se aplica.

Contribuições das autoras

O artigo é parte dos estudos realizados no processo de doutoramento ainda em curso no PPGSS/UFRJ.

\author{
Aprovação por Comitê de Ética e consentimento para \\ participação \\ Não se aplica. \\ Consentimento para publicação \\ Não se aplica. \\ Conflito de interesses \\ Não há conflito de interesses.
}

1 Importa salientar que nem sempre o capitalismo se constitui enquanto democrático. Ver Mascaro (2013).

2 A exemplo das novas tecnologias — Cadastro Único; e-SUS APS; e Meu INSS — postas no campo da seguridade social, capazes de empreender um regime de grande fluxo de informações via recursos bastante sofisticados, os quais possibilitarão acesso aos serviços.

3 Grohmann (2021, p. 41) entende as plataformas como meios de produção e comunicação. Infraestruturas, cadeias produtivas de valor, modos de gerenciamento da força de trabalho e organizadora dos processos produtivos.

4 De acordo com Behring e Boschetti (2011), o período pós-1990 pode ser considerado, no País, como de contrarreforma do Estado, posto que a denominada Reforma do Estado idealizada por Bresser Pereira (1998) marcou um retrocesso nas conquistas demarcadas na Carta de 1988, sobretudo, nas políticas públicas de previdência, de assistência social e de saúde.

5 Entende-se por contratendências as ações empreendidas pelo capital no sentido de contrapor a queda da taxa de lucro (IASI, 2017, p. 53-54).

6 Para Marshall, os direitos que constituem a cidadania em sua completude seriam os direitos civis, políticos e sociais, complementares entre si, sendo este último fundamental para alteração do padrão de desigualdade. (MARSHALL, 1967).

7 O Cadastro Único reúne um conjunto de informações sobre as famílias brasileiras em situação de pobreza e extrema pobreza.

8 Segundo a Pesquisa TIC domicílios de 2019, no Brasil, existem 47 milhões de pessoas que não acessam a rede de internet, ou seja, um a cada quatro brasileiros são excluídos digitalmente.

9 Cabe destacar que o governo estuda este modelo de autocadastro para o Bolsa Família, fato que pode impactar o financiamento da gestão e o esvaziamento das funções dos Centros de Referência da Assistência Social.

10 Auxílio Carioca - lançado em abril/2021, é de iniciativa da Prefeitura da Cidade do Rio de Janeiro, com pagamentos de auxílio de R \$200 a R \$ 500 aos ambulantes e artesãos cadastrados e excluídos do Cadastro Único, a fim de mitigar os impactos da pandemia da Covid-19; SuperaRJ - é um auxílio emergencial criado pelo Governo Estadual do Rio de Janeiro, iniciado em junho com previsão 
de término em dezembro/2021, destinado a cidadãos que precisam de algum tipo de suporte financeiro nesse momento de crise, com as novas ondas de Covid-19. O pagamento previsto é de R \$ 300 aos inscritos no Cadastro Único; Auxílio Emergencial - é um benefício financeiro do Governo Federal de caráter emergencial para enfrentamento da crise causada pela pandêmica do coronavírus destinado a trabalhadores informais, microempreendedores individuais (MEI), autônomos e desempregados. O benefício começou a valer em abril de 2020 com repasses de $\mathrm{R} \$ 600$, sendo suspenso em dezembro e retornado em 2021 com valores reduzidos: $\mathrm{R} \$$ 150 para solteiros, R 250 para famílias e R $\$ 375$ para mães solteiras (BRASIL, [2021]).

11 O documentário Coded Bias aborda a temática a partir do estudo de Joy Buolamwini.

12 Entrevista com a Virgínia Eubanks, autora do livro Automating Inequality, à Digilabour. 